\title{
Early season root production in relation to leaf production among six diverse temperate tree species
}

\author{
M. Luke McCormack • Katie P. Gaines • \\ Melissa Pastore • David M. Eissenstat
}

Received: 1 October 2014 / Accepted: 24 November 2014 / Published online: 5 December 2014

(C) Springer International Publishing Switzerland 2014

\begin{abstract}
Aims Leaf and root phenology play important roles controlling plant productivity and ecosystem function, yet, few studies link patterns of leaf and root phenology across woody species. Trees with diffuse-porous wood anatomy tend to leaf-out before ring-porous species and we expected that increases in transpiration with spring leaf-out would be coupled with initiation of root production to support uptake of soil resources. Therefore, we hypothesized that the timing of root production would follow patterns of leaf production and wood anatomy.
\end{abstract}

Responsible Editor: Alexia Stokes.

M. L. McCormack ( $\bowtie)$

Key Laboratory of Ecosystem Network Observation and Modeling, Institute of Geographic Sciences and Natural Resources Research, Chinese Academy of Sciences, 11A Datun RoadChaoyang DistrictBeijing 100101, China e-mail: mltmcc@gmail.com

M. L. McCormack • K. P. Gaines • D. M. Eissenstat Intercollege Graduate Degree Program in Ecology, The Pennsylvania State University,

State College, PA 16801, USA

K. P. Gaines $\cdot$ M. Pastore • D. M. Eissenstat

Department of Ecosystem Science and Management, The

Pennsylvania State University,

State College, PA 16801, USA

Present Address:

M. Pastore

Department of Biology, Villanova University,

Villanova, PA 19085, USA
Methods Root production was observed using minirhizotrons and related to leaf phenology across six temperate tree species with different wood anatomy in a common garden.

Results As expected, leaves of diffuse-porous species emerged before ring-porous, followed by tracheid species. Root production peaked before bud break in five of the six species and before maximum leaf area index in all species, but did not follow expected patterns with leaf production.

Conclusions Our observations did not indicate tight linkages between root and leaf phenology but do highlight the potential for very early season root production and greater variation in the phenology of roots than leaves. Future work should identify the environmental factors and species traits that best explain variation in root phenology.

Keywords Phenology $\cdot$ Ecosystem $\cdot$ Net primary production (NPP) · Minirhizotron · Belowground $\cdot$ Leaf area index (LAI)

\section{Introduction}

The timing of key events including bud burst, leaf expansion, and leaf senescence are well-recognized as important determinants of plant functioning and productivity in terrestrial ecosystems (Fridley 2012; Morin et al. 2009; Richardson et al. 2006). Recent research has also highlighted the role that aboveground phenology plays in determining species responses to climate 
change and potentially structuring plant communities (Diez et al. 2012; Fridley 2012; Inouye 2008). In contrast, observations of important events below ground including date of initial root growth and timing of peak root production are more difficult to obtain and relatively little is known about their variability among species and across years. This has also made it challenging to relate patterns of belowground phenology to wellestablished patterns of leaf phenology.

Temperate forests often contain a diverse mix of tree species that vary widely in their life history and leaf structure. Across this diversity, patterns of leaf phenology have emerged which may be based partially on wood anatomy (Lechowicz 1984). Among angiosperms, wood anatomy can often be characterized as either diffuse-porous or ring-porous, and the differences between the two have implications for the efficiency of water conductance through the plant, hydraulic safety margins, and overall wood density (Hacke and Sperry 2001; Wang et al. 1992). Differences in hydraulic safety are affected by wood anatomy, with larger-diameter xylem conduits more vulnerable to freezing-induced cavitation and more limited in conductivity early in the growing season compared to smaller-diameter vessels (Hacke and Sperry 2001). As a result, diffuse-porous species, with a higher margin of safety, are generally able to produce new leaves earlier in spring than neighboring ring-porous species (Lechowicz 1984; Wang et al. 1992). In contrast, because evergreen conifers retain leaves year-round, their patterns of new leaf emergence may not be related to their wood anatomy.

Belowground, temperate tree species also express a wide degree of variation in root anatomy, morphology, lifespan, and turnover (Kong et al. 2014; McCormack et al. 2012; Withington et al. 2006). While observations are limited, previous studies have indicated that fine root phenology also varies appreciably among species, although no broad patterns have been identified (Harris et al. 1995; Lyr and Hoffmann 1967; McCormack et al. 2014; Steinaker et al. 2010). Importantly, different patterns of fine root phenology may represent different ecological strategies among species. For example, production of roots in early spring may be a competitive strategy by some species to occupy favorable soil layers and access water or nutrients before neighboring plants (Eissenstat and Caldwell 1988; Harris 1977). Other species may vary patterns of root production in response to timing of carbohydrate availability from recent photosynthesis or carbohydrate demand by other plant tissues (e.g., leaves, stems, or reproduction) (Cardon et al. 2002; Dietze et al. 2014). Overall, there have been relatively few observations that link root phenology with whole-plant or ecosystem processes.

In this study, we monitored patterns of root production together with bud break and leaf emergence, expansion, and senescence across a growing season in a common garden in central Pennsylvania, USA (Fig. 1). Observations were made at relatively high frequencies (weekly during periods of leaf emergence and bi-weekly thereafter) to ensure that both root and leaf phenology could be accurately characterized. The six species used in this study represent a diverse set of temperate trees including two diffuse-porous angiosperms (Acer saccharum, Liriodendron tulipifera), two ring-porous angiosperms (Carya glabra, Quercus alba), and two evergreen (tracheid) gymnosperms (Pinus strobus, Pinus virginiana). In contrast to previous studies focusing on patterns of shoot elongation (Harris et al. 1995; Steinaker et al. 2010), we specifically focused on relating root production to patterns of leaf growth. We hypothesized that patterns of early season root phenology would follow patterns of leaf phenology. That is, we expected that diffuse-porous species that are characterized by earlier leaf-out should also exhibit earlier peak root production than that of ring-porous species. Furthermore, previous observations from this site have indicated that needle emergence in $P$. strobus and $P$. virginiana generally occurs later than leaf emergence in other species (McCormack pers. obsv.; www.usanpn. org, site 5281). Therefore, we expected that the deciduous angiosperms would be characterized by earlier leaf-out and earlier root production than the evergreen gymnosperm species. Linking patterns of root production to leaf production and wood anatomy enables a broader understanding of fine root phenology in relation to leaf and plant traits that have been wellstudied and whose mechanistic connections are already established.

\section{Materials and methods}

Study site

The common garden site is located in Russell E. Larson Agricultural Research Center in central Pennsylvania, USA $\left(40^{\circ} 42^{\prime} \mathrm{N} 77^{\circ} 57^{\prime} \mathrm{W}\right)$. The site has been previously described (McCormack et al. 2012) and consists of 16 

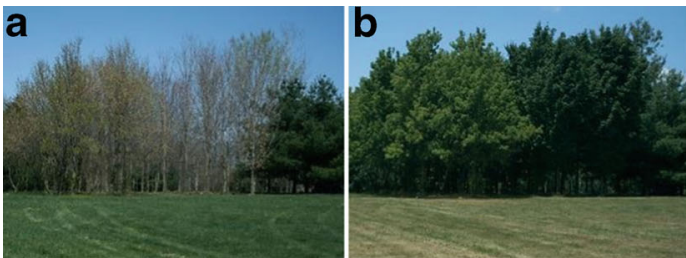

Fig. 1 Image sequence of the Rock Springs Common Garden in central Pennsylvania, USA. Moving from left to right, images were collected on March 26, July 8, October 9, and December
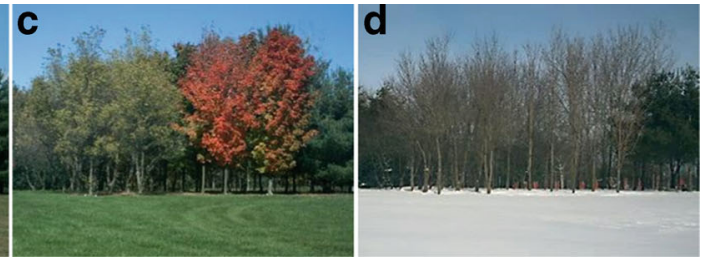

31 in 2012. The plot shown right of center, Acer saccharum, was used in this study (notice red-orange leaf coloring on October 9)

\section{Root observations}

Observations of fine root production were made using a Bartz 2.86-cm minirhizotron camera system with I-CAP version 4.01 software (Bartz Technology Corp., Carpinteria, CA, USA). Clear acrylic minirhizotron tubes (ID $=2.9 \mathrm{~cm}$, length $45 \mathrm{~cm}$ ) were installed in 2005 at an angle of $30^{\circ}$ from vertical. Each tube was located $30 \mathrm{~cm}$ from the base of a randomly selected individual within a given plot and at least $3.5 \mathrm{~m}$ from a neighboring plot to minimize edge effects. The tops of the tubes were wrapped in black vinyl tape and then covered with white aluminum cans to prevent light intrusion and minimize solar heating. For each imaging session, up to 20 images were collected along both the upper and lower surface of each tube to a vertical depth of $20 \mathrm{~cm}$, which generally represents the majority of fine roots produced by these species. Three tubes were used in each species plot in each of 4 blocks for a total of 72 tubes. Between March and October, 2012, a total of 20 imaging sessions were collected ( 50,000 images). Weed cloth was used to minimize herb growth directly adjacent to the tubes and foliar herbicide was used as needed, though shading by tree canopies made this

Table 1 Six species observed in a common garden in central Pennsylvania, USA, along with their phylogeny, basic wood anatomy, and mycorrhizal association

\begin{tabular}{|c|c|c|c|c|}
\hline Species & Family & Group & Wood Anatomy & Fungal Association* \\
\hline Acer saccharum & Aceraceae & Angiosperm & Diffuse porous & $\mathrm{AM}$ \\
\hline Carya glabra & Juglandaceae & Angiosperm & Ring porous & EM \\
\hline Liriodendron tulipifera & Magnoliaceae & Angiosperm & Diffuse porous & $\mathrm{AM}$ \\
\hline Pinus strobus & Pinaceae & Gymnosperm & Tracheid & EM \\
\hline Pinus virginiana & Pinaceae & Gymnosperm & Tracheid & EM \\
\hline Quercus alba & Fagaceae & Angiosperm & Ring porous & EM \\
\hline
\end{tabular}

*Refers to the primary type of mycorrhizal fungal association formed by each species; either arbuscular mycorrhizal fungi (AM) or ectomycorrhizal fungi (EM) 
largely unnecessary. During image analysis, roots were identified as being born when they first appeared on the surface of the tube. New roots were easy to differentiate from surrounding soil and soil fauna based on morphology and color. Images were analyzed using Rootfly v2.0.2 (Wells and Birchfield, Clemson University, SC, USA). Individual roots were monitored and their birth dates recorded to accurately assess timing of root birth.

Leaf observations

Leaf area index (LAI) was measured in each species plot and each session using a LI-COR LAI-2200 Plant Canopy Analyzer (LI-COR Biosciences, Nebraska, USA). Data were processed using the LI-COR FV2200 software. A sample collection protocol was chosen to allow measurement of LAI of each individual plot, including the use of a $45^{\circ}$ lens cap, and masking the outermost ring of data to minimize interference from neighboring plots. Above-canopy calibration measurements were collected in a nearby open field before, during, and after below-canopy measurements. Belowcanopy measurements for each plot were collected at six inward-facing positions per plot. Above-canopy measurements were linked with the "closest-in-time" belowcanopy measurements in the FV-2000 software. Data were collected early in the morning, or on overcast days whenever possible to avoid inaccurate readings from direct sunlight on the sensor.

Manual observations of bud burst, leaf emergence, and leaf expansion were also made at the same time as LAI measurements following protocols described by the US National Phenology Network (www.usanpn.org). These observations were recorded on two individual trees that were directly adjacent to installed minirhizotron tubes in each species plot. In this study, we report data based on the average initial date of bud burst and completion of leaf expansion. Full reports of these manual observations are available through the USA National Phenology Network (www.usanpn.org, site ID 5281- Rock Springs Common Garden).

\section{Analyses}

Mean LAI and standard error were calculated by species for each observation date in each block $(n=4)$. These were then normalized by the maximum LAI observed for each species. One LAI session date was removed (13-September) due to abnormally high values in each plot, which were most likely a result of direct sunlight on the sensor during above-canopy readings. Root production was standardized to daily production as the number of days between image sessions varied during the study. Therefore, the total number of new roots observed with a given imaging session was divided by the number of days between that and the previous session. This was then standardized based on the maximum value of root production per day for each species. As a measure of uncertainty, standard errors of the mean root production by sampling date were calculated using the observations from all tubes for each species. However, given the relatively low root production and frequent zero counts these values likely underestimate variability in the system but still reflect general patterns of variability across the season.

\section{Results}

Consistent with previous reports, bud break and leaf emergence began earlier in the diffuse-porous angiosperms than in the ring-porous angiosperms (Fig. 2, Table 2). Bud break occurred on day 93 (2-April \pm 2 days) and day 82 (22-March \pm 0 days) in A. saccharum and L. tulipifera, respectively, but not until day 134 (12-May \pm 2 days) for C. glabra and day 115 (24-April \pm 3 days) for Q. alba (Table 2, Fig. 3). In the two evergreen species, $P$. strobus and $P$. virginiana, needles began to emerge on day 129 ( \pm 5 days) and 122 ( \pm 2 days), respectively. All species reached $>85 \%$ of their maximum LAI around day 153 ( \pm 10 days). The period of active leaf/needle expansion recorded with manual observations ended by day 160 or 170 in the deciduous angiosperms but continued through day 210 in the pine species (shaded green region in Fig. 3). At the end of the growing season, the timing of leaf senescence was similar across all species and LAI fell below $85 \%$ by day 272 for all species, including the evergreens. However, the apparent similarity in timing of leaf senescence may have been a result of the reduced frequency of observations in fall compared to spring (i.e. bi-weekly instead of weekly) masking finer scale differences.

Belowground, soil temperatures at a $20 \mathrm{~cm}$ depth reached $10.0{ }^{\circ} \mathrm{C}$ relatively early (day 76 ) and remained between 9 and $12{ }^{\circ} \mathrm{C}$ until day 121, after which soil and air temperatures climbed steadily until leveling off at around $24^{\circ} \mathrm{C}$ after day 185 (Fig. 2). Root production 
Fig. 2 Soil temperature at $20 \mathrm{~cm}$ depth (dark gray line) and air temperature (light gray line) recorded in the Russell E. Larson Agricultural Research Center in central Pennsylvania, USA, with corresponding above- and belowground phenophases in year 2012. Phenophases are reported for six temperate tree species and include the period from first observed root production to peak root production (brown bars), duration of active bud break (light green bars), and duration of active leaf expansion (dark green bars)

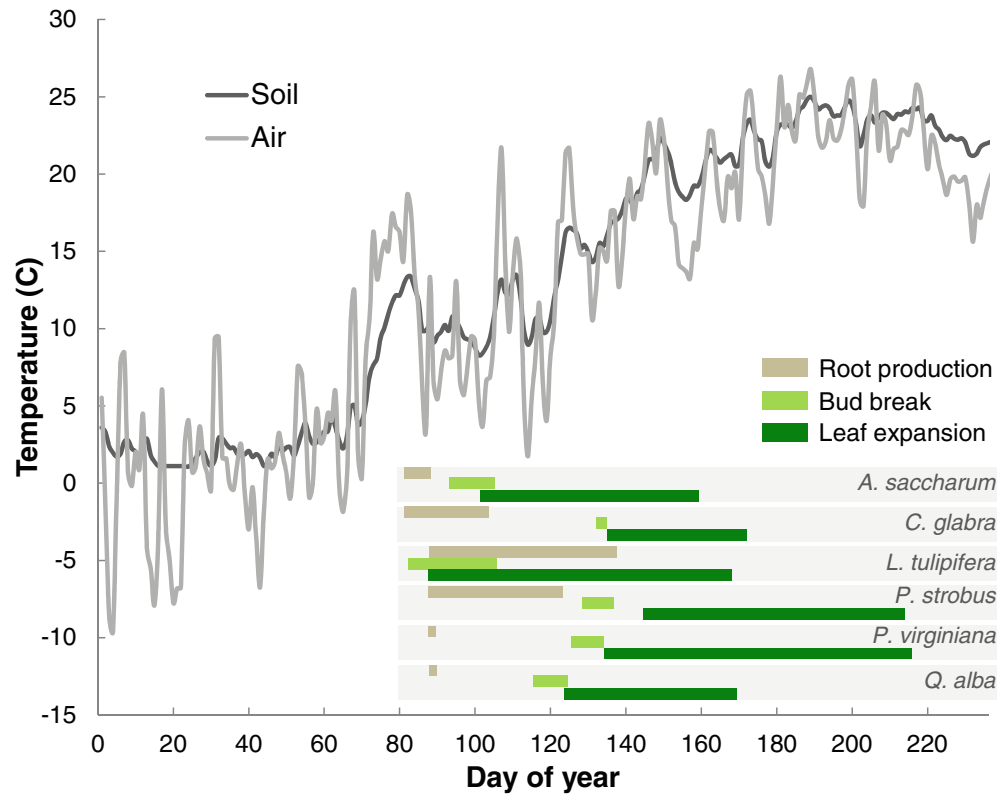

was observed in all six species before 1-April (Table 2, day 82-89). Peak root production occurred in late March or early April in four of the six species and only a few weeks later ( day 130) in L. tulipifera and P. strobus (Figs. 2 and 3). For most species, root production gradually declined after the early season peak until mid-summer ( day 200), after which relatively few roots were produced. Still, some root production was observed after day 250 ( $\sim$ September) in three of the six species (A. saccharum, C. glabra, P. strobus), indicating that late season production was possible for many species.

Contrary to our hypothesis, there was no clear ordering of peak root production in relation to leaf production. The first day of root production (day 82) was the same for A. saccharum, which had early leaf emergence, and for C. glabra, with late leaf emergence. All other species produced roots within the next week. Furthermore, peak root production in L. tulipifera occurred after all other species despite having the earliest

Table 2 Day of year $( \pm$ SE) for different above- and below-ground phenological events in 6 temperate species recorded in a common garden in central Pennsylvania, USA, in 2012

\begin{tabular}{|c|c|c|c|c|c|c|c|}
\hline \multirow[t]{2}{*}{ Species } & \multicolumn{2}{|c|}{ Bud Break (d) } & \multicolumn{2}{|c|}{ Leaf Expansion (d) } & \multicolumn{2}{|c|}{ Root Production (d) } & \multirow[t]{2}{*}{ No. Roots } \\
\hline & Min & $\operatorname{Max}$ & Min & $\operatorname{Max}$ & First & Peak & \\
\hline A. saccharum & $93(2.2)$ & $105(0.9)$ & $102(2.7)$ & $159(8.2)$ & 82 & 89 & 19 \\
\hline C. glabra & $134(0.3)$ & $135(0.3)$ & $137(0.3)$ & $173(1.0)$ & 82 & 104 & 54 \\
\hline L. tulipifera & $82(0)$ & $105(1.7)$ & $89(0)$ & $168(5.0)$ & 89 & 138 & 37 \\
\hline P. strobus & $129(3.0)$ & $137(3.5)$ & $144(0.9)$ & $212(3.6)$ & 89 & 124 & 14 \\
\hline P. virginiana & $125(2.9)$ & $133(1.5)$ & $133(1.5)$ & $213(2.1)$ & 89 & 89 & 15 \\
\hline Q. alba & $116(2.8)$ & $124(1.4)$ & $123(2.6)$ & $168(4.4)$ & 89 & 89 & 38 \\
\hline
\end{tabular}

Bud Break Min and Max refer to the earliest and latest day where active bud break was observed while Leaf Expansion Min and Max refer to the first day were active leaf emergence and expansion was observed and last day where active leaf expansion was observed, respecitvely. Root Production First and Peak refer to the first day root production was observed and the day when root production peaked, respectively. No. Roots is the total number of roots observed over the growing season for each species 


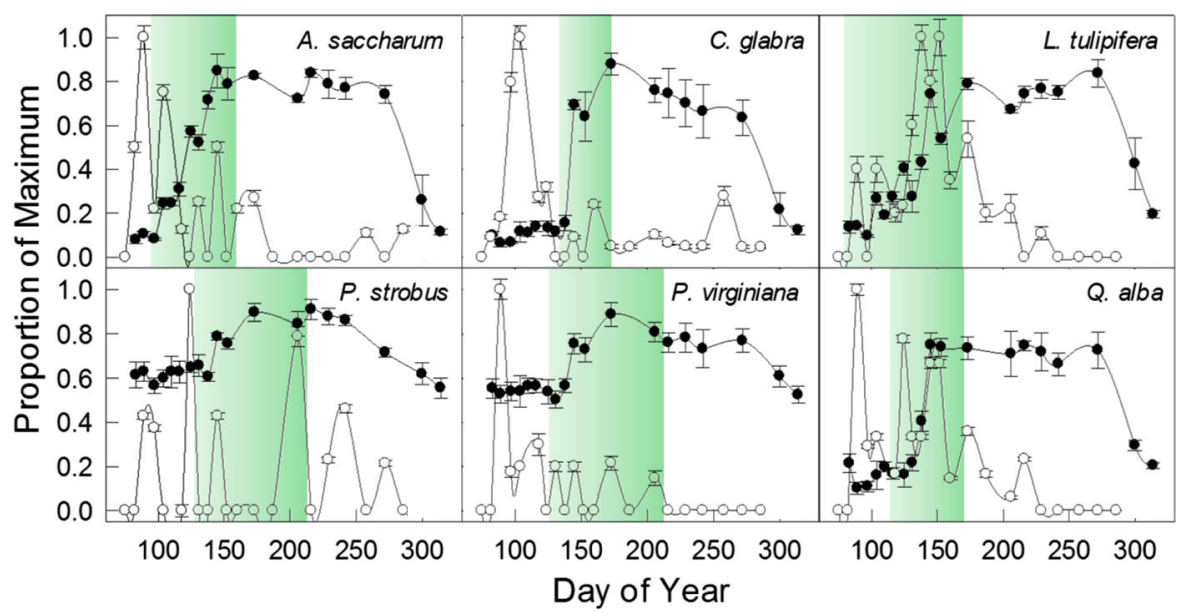

Fig. 3 Proportional leaf area index and root production observed in six temperate tree species across the 2012 growing season in central Pennsylvania, USA. Each point represents an observation

bud break and leaf emergence of all six species. Root production peaked before maximum LAI in all species and before bud break in five of the species (Fig. 3). Only in L. tulipifera was there apparent synchrony between root and leaf production. Diffuse-porous species tended to produce a greater proportion of their roots after bud break than ring porous or tracheid species $(P<0.001)$. However, this pattern appeared to be largely driven by the late root production in L. tulipifera and early bud break in L. tulipifera and A. saccharum.

\section{Discussion}

Studies liking leaf and root phenology together with high temporal precision are scarce. Observations of fine-root and leaf phenology across six temperate species within the common garden indicated that fine root production may variably precede or follow leaf emergence in spring depending on species and year. Furthermore, we found little evidence that the timing of peak root production was broadly related to timing of leaf phenology among functionally different groups of species (i.e. deciduous angiosperms with either ring porous or diffuse porous wood anatomy, or evergreen gymnosperms).

Previous observations from this site identified wide variation in root phenology among species (McCormack et al. 2014). While the frequency of root observations in the earlier study was insufficient to
$( \pm \mathrm{SE})$ for leaf area index (closed circles) and root production (open circles). The shaded green area represents the period between first bud break to complete leaf/needle expansion

describe fine-scale differences in phenology, comparisons between those data and data reported here highlight key differences among species. First, the date of peak root production in L. tulipifera reported here (year 2012) was nearly identical to all previous years of observation (2008, 2009, and 2010). At the same time, most other species demonstrated substantial variability in timing of root production. Even $Q$. alba, which had relatively consistent timing of root production in the previous years, showed a strong shift towards earlier peak root production in year 2012 (50 to 100 days earlier). Some of the apparent shift to earlier production in this study could have been due to early season production being missed in the previous study where observations generally began in April instead of March. However, if this were true, a large pulse of roots should have been observed at the first imaging sessions in years 20082010, which was not the case. A more likely factor contributing the early root production may be related to warmer than average spring temperatures in 2012.

Changes in soil temperature have been linked with patterns of root production in previous studies. It is generally expected that temperatures at or near freezing inhibit absorptive root growth and as spring temperatures increase above freezing so too does root production (Burke and Raynal 1994; Steele et al. 1997; Teskey and Hinckley 1981; Tierney et al. 2003). In this study, spring soil temperatures reached key thresholds of 5 and $10{ }^{\circ} \mathrm{C}$ roughly 1 to 3 weeks earlier than in most previous years (data not shown) which may partially explain the 
strong root growth in early spring that in many species preceded leaf emergence (Fig. 3). Beyond the date of first root emergence, peak root production, which usually occurs later in summer, also occurred much earlier in the 2012 growing season than was expected based on previous years of observation.

In temperate and boreal ecosystems the link between root production and temperature often continues well into the growing season with peak root production generally occurring near or just below peak soil temperatures (Steele et al. 1997; Steinaker et al. 2010; Teskey and Hinckley 1981). In contrast, we observed relatively little root production after late spring. The lack of a summer pulse in root growth may be responsible for the strong shift in timing of peak root production observed for most species (except L. tulipifera). For example, the timing of peak root production reported here was between 50 and 100 days earlier in 2012 for Q. alba, P. virginiana, and C. glabra compared with observations in years 2008-2010 (McCormack et al. 2014). In each of these species, very little root production was observed after day 160 in year 2012 which was well-before dates of peak production previously observed between days 180 and 200. Reasons for muted summer root production at this site are unclear. In some ecosystems water can serve as a key factor controlling the birth and death of roots, particularly those which experience pulsed or strong seasonal patterns of water availability (Salguero-Gómez and Casper 2011). However, the mesic climate and well-distributed annual precipitation generally experienced at the site, including year 2012, make limited water availability unlikely to be the dominant force controlling root growth in this study.

While we did not find support for the hypothesis that patterns of root phenology reflect patterns of leaf phenology, our data highlight two key aspects of combined root and leaf production phenology. First, speciesspecific patterns of root production are likely to be more variable among years than leaf production. This is clearly shown by 4 years of observation in our common garden as well as in other studies reporting multiple years of species-specific root observations (Côté et al. 1998; Eissenstat et al. 2006; Palacio and MontserratMartí 2007). Second, in ecosystems that experience seasonal dormancy, early spring root production may precede leaf production in many species. Data reported here consistently showed that initiation of root production and even peak root production can occur before leaf emergence. However, other studies indicate that it may also be common for the opposite to be true with aboveground production preceding root production (Harris et al. 1995; Lyr and Hoffmann 1967; Steinaker et al. 2010). In either case, it will be important for future root studies that do not continue observations year-round to initiate new data collection at least several weeks or months before typical spring leaf-out begins to ensure accurate characterization of root phenology.

Several questions still remain regarding root phenology and its relationship to leaf phenology. 1) Why do some species have conserved patterns of root phenology (e.g. L. tulipifera) while others express large interannual variability? While we did not identify consistent patterns of seasonal root production among species of different wood anatomy, continued effort is needed to identify which species traits are linked to root phenology. 2) How do different environmental drivers contribute to variation in root phenology? It is reasonably well established that growth in temperate systems is impaired when temperatures are near freezing or below. As temperatures increase above freezing, root production normally increases (Burke and Raynal 1994; Joslin et al. 2001; Steele et al. 1997; Teskey and Hinckley 1981; Tierney et al. 2003). Additionally, changes in water availability may also trigger increases or decreases in root production (Joslin et al. 2001; Reich et al. 1980; Teskey and Hinckley 1981). However, shifts in timing of peak root production in excess 50 days as observed in this study eclipse the relatively small differences in annual spring temperature and soil moisture that occurred in our site. Broader shifts in root production may be driven by a combination of local, recent environmental conditions as well as climatic conditions and plant productivity (i.e. availability of carbohydrates) of the previous growing season(s). As such, a long view of climate effects on root phenology may be necessary in addition to more direct correlations of root production with recent patterns of temperature and moisture. 3) How does shifting root phenology from pre- to postleaf emergence impact whole-plant stores of carbohydrates and subsequent allocation to other plant components during the growing season? It is intuitively understood that construction of new leaves of deciduous species in spring must rely on stored carbohydrates. Conversely, it is less well known what proportion of new versus old carbohydrates are used in fine root production or what the broader implications are with shifts between the two (Vargas et al. 2009; Lynch et al. 2013). Previous studies have identified potential trade- 
offs between fine root production and other plant components (i.e. wood production) (Litton et al. 2007; Malhi et al. 2011). However, it is not clear how total annual allocation to each biomass pool will be favored or reduced by shifting the timing of root production from early spring before leaf emergence to late spring or summer after leaf emergence.

Identifying patterns and variation in fine root phenology across species represents a basic and necessary step to improve understanding of plant and ecosystem processes, especially in the context of climatic change. Future research focusing on variation across species as well as within a species but across years will both be important. Furthermore, linking detailed patterns of carbohydrate allocation among leaves and roots can help to explain variation in phenology and may identify more physiologically-based links between root and leaf phenology. While reports based on observations made in mixed-species ecosystems are useful, species-specific observations may be required to tease apart key differences across ecosystems and through time. Furthermore, in order to ensure that periods of active root production are not missed, observations will likely need to begin earlier in the growing season than has been typical of many previous studies.

Acknowledgments The authors thank T. Adams for assistance in the lab and field. This work was supported by National Science Foundation (NSF) (ARC-1107381 and IOS-1120482) to DME; Chinese Academy of Sciences, National Natural Science Foundation of China (No. 31350110503), and the United States DOE GREF to MLM; NSF GK-12 CarbonEARTH (0947962) to KPG; and NSF SSHCZO Zone Observatory (EAR 07-25019 \& EAR 12-39285).

Conflict of interest The authors declare no conflict of interest.

\section{References}

Burke MK, Raynal DJ (1994) Fine-Root Growth Phenology, Production, and Turnover in a Northern Hardwood. For Ecosyst Plant Soil 162:135-146

Cardon ZG, Czaja AD, Funk JL, Vitt PL (2002) Periodic carbon flushing to roots of Quercus rubra saplings affects soil respiration and rhizosphere microbial biomass. Oecologia 133: 215-223

Côté B, Hendershot WH, Fyles JW, Roy AG, Bradley R, Biron PM, Courchesne F (1998) The phenology of fine root growth in a maple-dominated ecosystem: relationships with some soil properties. Plant Soil 201:59-69,\%@0032-0079X
Dietze MC, Sala A, Carbone MS, Czimczik CI, Mantooth JA, Richardson AD, Vargas R (2014) Nonstructural carbon in woody plants. Ann Rev Plant Biol 65

Diez JM et al (2012) Forecasting phenology: from species variability to community patterns. Ecol Lett 15:545-553

Eissenstat DM, Caldwell MM (1988) Seasonal timing of root growth in favorable microsites. Ecology 69:870-873

Eissenstat DM, Bauerle TL, Comas LH, Lakso AN, Neilsen D, Neilsen GH, Smart DR (2006) Seasonal patterns of root growth in relation to shoot phenology in grape and apple. Acta Hortic 721:21-26

Fridley JD (2012) Extended leaf phenology and the autumn niche in deciduous forest invasions. Nature 485:359-362

Hacke UG, Sperry JS (2001) Functional and ecological xylem anatomy. Perspect Plant Ecol Evol Syst 4:97-115

Harris GA (1977) Root phenology as a factor of competition among grass seedlings. J Range Manag 30:172177

Harris JR, Bassuk NL, Zobel RW, Whitlow TH (1995) Root and shoot growth periodicity of green ash, scarlet oak Turkish hazelnut, and tree lilac. J Am Soc Hortic Sci 120:211-216

Inouye DW (2008) Effects of climate change on phenology, frost damage, and floral abundance of montane wildflowers. Ecology 89:353-362

Joslin JD, Wolfe MH, Hanson PJ (2001) Factors controlling the timing of root elongation intensity in a mature upland oak stand. Plant Soil 228:201-212

Kong D, Li L, Ma C, Zeng H, Guo D (2014) Leading dimensions of root trait variation in subtropical forests. New Phytol. doi: 10.1111/nph.12842

Lechowicz MJ (1984) Why do temperate deciduous trees leaf out at different times?Adaptation and ecology of forest communities. Am Nat 124:821-842

Litton CM, Raich JW, Ryan MG (2007) Carbon allocation in forest ecosystems. Global Chang Biol 13:2089-2109. doi: 10.1111/j.1365-2486.2007.01420.x

Lynch DJ, Matamala R, Iversen CM, Norby RJ, Gonzalez-Meler MA (2013) Stored carbon partly fuels fine-root respiration but is not used for production of new fine roots New Phytologist 199:420-430

Lyr H, Hoffmann G (1967) Growth rates and growth periodicity of tree roots. Int Rev For Res 2:181-236

Malhi Y, Doughty C, Galbraith D (2011) The allocation of ecosystem net primary productivity in tropical forests. Philos Trans Royal Soc B: Biol Sci 366:3225-3245

McCormack ML, Adams TS, Smithwick EA, Eissenstat DM (2012) Predicting fine root lifespan from plant functional traits in temperate trees. New Phytol 195:823-831. doi:10. 1111/j.1469-8137.2012.04198.x

McCormack ML, Adams TS, Smithwick EA, Eissenstat DM (2014) Variability in root production, phenology, and turnover rate among 12 temperate tree species. Ecology 95:2224 2235. doi:10.1890/13-1942.1

Morin X, Lechowicz MJ, Augspurger C, O’ Keefe J, Viner D, Chuine I (2009) Leaf phenology in 22 North American tree species during the 21st century. Glob Chang Biol 15:961975. doi:10.1111/j.1365-2486.2008.01735.x

Palacio S, Montserrat-Martí G (2007) Above and belowground phenology of four Mediterranean sub-shrubs. Preliminary results on root-shoot competition. J Arid Environ 68:522533 
Reich PB, Teskey RO, Johnson PS, Hinckley TM (1980) Periodic root and shoot growth in oak. For Sci 26:590-598

Richardson AD, Bailey AS, Denny EG, Martin CW, O'Keefe J (2006) Phenology of a northern hardwood forest canopy. Glob Chang Biol 12:1174-1188. doi:10.1111/j.1365-2486.2006.01164.x

Salguero Gómez R, Casper BB (2011) Introducing short roots in a desert perennial: anatomy and spatiotemporal foraging responses to increased precipitation. New Phytol 191:173-183

Steele SJ, Gower ST, Vogel JG, Norman JM (1997) Root mass, net primary production and turnover in aspen, jack pine, and black spruce forests i Saskatchewan and Manitoba, Canada Tree Physiology 17:577-587

Steinaker DF, Wilson SD, Peltzer DA (2010) Asynchronicity in root and shoot phenology in grasses and woody plants. Glob Chang Biol 16:2241-2251. doi:10.1111/j.1365-2486.2009. 02065.x
Teskey RO, Hinckley TM (1981) Influence of temperature and water potential on root growth of white oak. Physiol Plant 52: 363-369

Tierney GL, Fahey TJ, Groffman PM, Hardy JP, Fitzhugh RD, Driscoll CT, Yavitt JB (2003) Environmental control of fine root dynamics in a northern hardwood forest. Glob Chang Biol 9:670-679

Vargas R, Trumbore SE, Allen MF (2009) Evidence of old carbon used to grow new fine roots in a tropical forest New Phytologist 182:710-718

Wang J, Ives NE, Lechowicz MJ (1992) The relation of foliar phenology to xylem embolism in trees. Funct Ecol:469-475

Withington JM, Reich PB, Oleksyn J, Eissenstat DM (2006) Comparisons of structure and life span in roots and leaves among temperate trees. Ecol Monogr 76:381-397 